\title{
Survival and cause of death in a cohort of patients with parkinsonism: possible clues to aetiology?
}

\author{
Yoav Ben-Shlomo, M G Marmot
}

\begin{abstract}
Most previous studies that have examined the survival of patients with parkinsonism have recruited them from specialist centres. No previous study has ever reported cause specific mortality. We report on the mortality of a cohort of 220 parkinsonian patients recruited between 1970 and 1972 from 40 primary health care practices all over England and Wales and matched to 421 controls. At 20 years of follow up, 195 cases $(88 \cdot 6 \%)$ and 295 controls $(70 \cdot 1 \%)$ were no longer alive $(P<0.001)$. The median age at death for cases was 77.6 (range 53.8-97.3) and $83 \cdot 5$ (range $55 \cdot 0-100 \cdot 1$ ) for controls $(P<0.001)$. The all cause hazard ratio for cases compared with controls was $2 \cdot 6$ (95\% confidence interval (95\% CI) $2 \cdot 2-3 \cdot 2)$ controlling for age, sex, and geographical region. There was little difference between men and women. Differences for cause specific mortality also emerged. Both ischaemic heart disease $(2 \cdot 3,95 \%$ CI $1 \cdot 5-3 \cdot 4)$ and cerebrovascular disease $(3 \cdot 6,95 \%$ CI $2 \cdot 2-6 \cdot 1)$ showed significantly increased hazard ratios. Possible reasons for these findings are discussed in terms of (a) competing causes of death, (b) a secondary effect of drug treatment, and (c) common aetiological factors for both parkinsonism and cardiovascular disease.
\end{abstract}

(F Neurol Neurosurg Psychiatry 1995;58:293-299)

Keywords: Parkinson's disease; aetiology

The introduction of levodopa treatment in the late 1960s had a clear and dramatic effect on the symptoms of patients with Parkinson's disease. Unfortunately no randomised placebo controlled trial was ever established. It is generally assumed that the introduction of levodopa treatment has improved the relative mortality for parkinsonian cases compared with the rest of the population. Most previous research has either been based on case series without healthy control data ${ }^{12}$ or has used comparative routine mortality statistics. $^{3-14}$ All but two of these studies used national mortality, which may not be appropriate due to variations in regional mortality. Two studies have compared the mortality of parkinsonian cases with relevant matched controls. ${ }^{1516}$ (See table 1 for a summary of other studies.) One of these ${ }^{15}$ used hospital controls and may have underestimated the relative mortality as such controls are more likely to have other serious diseases. Almost all of these studies have recruited their cases from specialist neurology units. This is problematic as specialist units may, in general, recruit more atypical and severe cases of neurological diseases. ${ }^{17}$ Only one study has been based on the follow up of a representative population based sample. ${ }^{16}$ This study importantly reported that parkinsonian cases had a $2 \cdot 5$-fold greater relative risk of dying than the general population, similar and only slightly improved on the relative mortality seen for the prelevodopa era. ${ }^{4}$ This result was based on follow up for only a 3.5 year period.

Cause of death among parkinsonian patients may provide a useful insight into aetiology. If they are also more likely to die of another disease, there may be a common genetic or environmental link between these disorders. No previous study has ever examined cause specific mortality of Parkinsonian cases compared with the general population.

We have examined both total and cause specific mortalities of a cohort of parkinsonian cases and matched population based controls recruited from primary health care facilities followed up for a 20 year period. This avoids previous methodological problems concerning ascertainment bias and the choice of an appropriate comparative group. Our aims were (a) to determine whether the mortality of parkinsonian cases had improved since the introduction of levodopa; (b) to determine whether any possible clue to the aetiology of parkinsonism might be found if these cases were more or less likely to die of other diseases.

\section{Subjects and methods}

The cohort of parkinsonian cases and controls was derived from 64 general practices throughout England and Wales that took part in the Second National Morbidity study. ${ }^{18}$ The diagnoses for all patient episodes were recorded for a one year period. All subjects were recruited into the cohort between 25 November 1970 and 23 November 1972. In 1981 , the computerised records were used to identify all patients with a diagnostic code of Parkinson's disease. Two controls were randomly selected from the register of the same practice and matched by sex and same year of birth. The NHS numbers of all subjects were sent to the National Health Service Central Register to determine vital status. All deaths were subsequently informed to us by flagging 
Table 1 Studies reporting mortality for Parkinsonian cases compared with the general population *

\begin{tabular}{|c|c|c|c|c|c|}
\hline Authors & $\begin{array}{l}\text { Period of } \\
\text { recruitment }\end{array}$ & $\begin{array}{l}\text { Sample } \\
\text { size }\end{array}$ & $\begin{array}{l}\text { Method of } \\
\text { recruitment }\end{array}$ & $\begin{array}{l}\text { Comparative } \\
\text { data }\end{array}$ & $\begin{array}{l}\text { Mortality rate } \\
\text { ratiost }\end{array}$ \\
\hline \multicolumn{6}{|l|}{ Prelevodopa: } \\
\hline Nobrega et al & $1935-66$ & 203 & $\begin{array}{l}\text { Rochester residents, } \\
\text { USA }\end{array}$ & $\begin{array}{l}\text { Rochester age specific } \\
\text { mortality }\end{array}$ & 1.6 \\
\hline Hoehn and $\mathrm{Yahr}^{4}$ & $1949-64$ & $856(271)$ & $\begin{array}{l}\text { Neurology clinic, } \\
\text { New York, USA }\end{array}$ & $\begin{array}{l}\text { USA life tables } \\
1960\end{array}$ & $2 \cdot 9$ \\
\hline $\begin{array}{l}\text { Postlevodopa: } \\
\text { Zumstein et al }\end{array}$ & $1969-71$ & 1155 & $\begin{array}{l}\text { ? Neurology clinic, Zurich, } \\
\text { Switzerland }\end{array}$ & Swiss mortality data & $1 \cdot 0$ \\
\hline Diamond and Markham ${ }^{6}$ & $1968-69$ & 1087 & 20 medical centres, USA & USA life tables & 1.03 \\
\hline Hoehn $^{7}$ & $1968-82$ & 182 & $\begin{array}{l}\text { Neurology clinic, Denver, } \\
\text { USA }\end{array}$ & $\begin{array}{l}\text { USA Public Health life tables } \\
1971-81\end{array}$ & $1 \cdot 2$ \\
\hline $\begin{array}{l}\text { Joseph } \text { et }^{8}{ }^{8} \\
\text { Diamond and Markham }\end{array}$ & $\begin{array}{l}1969 \\
1972-74\end{array}$ & $\begin{array}{r}1625 \\
327\end{array}$ & $\begin{array}{l}29 \text { neurologists, USA } \\
19 \text { neurologists, USA }\end{array}$ & $\begin{array}{l}\text { ?USA life tables } \\
\text { USA mortality data }\end{array}$ & $\begin{array}{l}1.33 \text { adjusted for dropouts } \\
1.42\end{array}$ \\
\hline Rinne et al ${ }^{10}$ & $1969-78$ & 349 & $\begin{array}{l}\text { Neurology centre, Turku, } \\
\text { Finland }\end{array}$ & ? Finnish life tables & 1.6 \\
\hline Rajput et $a l^{14}$ & $1967-79$ & 138 & $\begin{array}{l}\text { Rochester residents, } \\
\text { USA }\end{array}$ & $\begin{array}{l}\text { Age and sex matched hospital } \\
\text { controls }\end{array}$ & \multirow{2}{*}{$\begin{array}{l}1.6 \text { (mortality of patients } \\
\text { treated with levodopa noted to } \\
\text { be no different from controls) } \\
1.9\end{array}$} \\
\hline Cedarbaum and McDowell" & 1968 & 100 & $\begin{array}{l}\text { New York medical centre, } \\
\text { USA }\end{array}$ & $\begin{array}{l}\text { ?USA age-sex } \\
\text { mortality }\end{array}$ & \\
\hline Diamond et $a l^{12}$ & $1968-70$ & 359 & Four centres, USA & USA mortality data & $2 \cdot 14$ \\
\hline Ebmeier et al ${ }^{15}$ & ? 1984 & 267 & $\begin{array}{l}\text { Population based ascertainment, } \\
\text { Aberdeen, Scotland }\end{array}$ & $\begin{array}{l}\text { General practice matched } \\
\text { controls by sex and age }\end{array}$ & $2 \cdot 35$ \\
\hline Curtis et $a l^{13}$ & 1969-72 & 176 & Neurology clinic, London, UK & $\begin{array}{l}\text { London age specific } \\
\text { mortality }\end{array}$ & $2 \cdot 6$ \\
\hline
\end{tabular}

*Where the results of a cohort have been published after varying periods of follow up, only the longest period is cited.

tA mortality rate ratio is the relative mortality of parkinsonian cases compared with a control population; a ratio greater than 1.0 indicates worse mortality for patients with Parkinson's disease.

the relevant records. As subjects died at different geographical locations, the cause of death would have been recorded by different doctors. No subjects were directly approached and the diagnosis of Parkinson's disease was not validated. Information on age, sex, case or control status, and area of residence was collected for all subjects. Residence was used to classify all subjects into four regional areas: southern England, midlands, northern England, and Wales.

All entries on the death certificate were coded from the ninth revision of the International Classification of Diseases. Cause of death was coded with standard rules. All the causes of death were checked before analysis by one of us (YB-S). Care was taken to follow the World Health Organisation (WHO) rule 3 in determining cause of death. For example, if bronchopneumonia was the sole entry in part I and Parkinson's disease was mentioned in part II, Parkinson's disease was coded as the cause of death. The following analysis presents data up to December 1991, which provides an average of 20 years of follow up.

Death has been classified as being due to ischaemic heart disease (IHD; ICD codes 410-414), cerebrovascular disease (ICD codes 430-438), neoplasm of trachea, bronchus, and lung (ICD code 162), or any neoplasm (ICD codes 140-239), chronic obstructive airways disease (ICD codes 490-496), other respiratory disease (ICD codes 460-519, but excluding chronic obstructive airways disease). Neoplasms have also been classified according to whether smoking is considered to play a part in their aetiology. ${ }^{19} 20$ The causes deemed to be smoking related, with their ICD codes, are: malignant neoplasms of the lip (ICD 140), tongue (141), mouth and pharynx (143-149), oesophagus (150), pancreas (157), respiratory system neoplasms (160-163), bladder (188), malignant neoplasms of unspecified site, or secondary neoplasms (195-199). All other cancers were classified as not smoking related.

\section{STATISTICAL ANALYSIS}

Differences in proportions and continuous variables were tested with the CochranMantel-Haenszel statistic and by analysis of variance respectively. If a continuous variable was highly skewed the Wilcoxon test was used. Each subject's person-time at risk was calculated from the date of entry until the date of death. If they had not died at the end of the follow up period they were censored. The survival function for the cohort and relevant sub-groups was initially examined with Kaplan-Meier plots. The difference in mortality for cases and controls was examined in a Cox's proportional hazard model. Univariate and multivariate estimates were calculated after adjustment for relevant covariates. Multivariate estimates were adjusted for age as a continuous variable and sex and region as dummy variables. The effect of using age as a quadratic term and potential interactions between case status and region were examined. Both all cause and cause specific mortality were used as outcome variables. Underlying assumptions of proportionality were tested by visually inspecting KaplanMeier plots for different subgroups. An interaction term for subgroup multiplied by the logarithm of time was also included in a Cox's proportional hazard model, as a more formal statistical test.

Standardised rate ratios were calculated from previously published papers using observed and expected deaths for women compared with men. This was done with the "confidence interval analysis" program. This assumes that the age specific mortality ratios for women and men are proportional to the standard rates. ${ }^{21}$ 
Table 2 Major causes of death for patients with parkinsonism and controls by sex after 20 years of follow up. (Number (\%) dead from that cause of death)

\begin{tabular}{|c|c|c|c|c|c|c|}
\hline & \multicolumn{3}{|l|}{$P D$ cases } & \multicolumn{3}{|l|}{ Controls } \\
\hline & $\begin{array}{l}\text { Men } \\
(n=93)\end{array}$ & $\begin{array}{l}\text { Women } \\
(n=127)\end{array}$ & $\begin{array}{l}\text { Total } \\
(n=220)\end{array}$ & $\begin{array}{l}\text { Men } \\
(n=171)\end{array}$ & $\begin{array}{l}\text { Women } \\
(n=250)\end{array}$ & $\begin{array}{l}\text { Total } \\
(n=421)\end{array}$ \\
\hline $\begin{array}{l}\text { Total deaths } \\
\text { Cause of death: }\end{array}$ & $83(100)$ & $112(100)$ & $195(100)$ & $125(100)$ & $170(100)$ & $295(100)$ \\
\hline $\begin{array}{l}\text { Neoplasms } \\
\text { Smoking related } \\
\text { Lung cancer } \\
\text { Non-smoking related } \\
\text { Ischaemic heart disease } \\
\text { Cerebrovascular disease } \\
\text { Chronic obstructive airways }\end{array}$ & $\begin{array}{c}2(2 \cdot 4) \\
1(1 \cdot 2) \\
0(0) \\
1(1 \cdot 2) \\
20(24 \cdot 1) \\
14(16 \cdot 9)\end{array}$ & $\begin{array}{l}7(6 \cdot 3) \\
2(1 \cdot 8) \\
0(0) \\
5(4 \cdot 5) \\
25(22 \cdot 3) \\
19(17 \cdot 0)\end{array}$ & $\begin{array}{l}9(4 \cdot 6) \\
3(1 \cdot 5) \\
0(0) \\
6(3 \cdot 1) \\
45(23 \cdot 1) \\
33(16 \cdot 9)\end{array}$ & $\begin{array}{l}27(21 \cdot 6) \\
19(15 \cdot 2) \\
12(9 \cdot 6) \\
8(6 \cdot 4) \\
36(28 \cdot 8) \\
10(8 \cdot 0)\end{array}$ & $\begin{array}{l}21(12 \cdot 4) \\
8(4 \cdot 7) \\
2(1 \cdot 2) \\
13(7 \cdot 6) \\
41(24 \cdot 1) \\
32(18 \cdot 8)\end{array}$ & $\begin{array}{l}48(16 \cdot 3) \\
27(9 \cdot 2) \\
14(4 \cdot 8) \\
21(7 \cdot 1) \\
77(26 \cdot 1) \\
42(14 \cdot 2)\end{array}$ \\
\hline $\begin{array}{l}\text { disease } \\
\text { Other respiratory disease } \\
\text { Other diseases }\end{array}$ & $\begin{array}{c}4(4 \cdot 8) \\
10(12 \cdot 0) \\
33(39 \cdot 8)\end{array}$ & $\begin{array}{l}1(0 \cdot 9) \\
17(15 \cdot 2) \\
43(38 \cdot 4)\end{array}$ & $\begin{array}{c}5(2 \cdot 6) \\
27(13 \cdot 8) \\
76(39 \cdot 0)\end{array}$ & $\begin{array}{l}13(10 \cdot 4) \\
15(12 \cdot 0) \\
24(19 \cdot 2)\end{array}$ & $\begin{array}{l}1(0 \cdot 6) \\
19(11 \cdot 2) \\
56(32 \cdot 9)\end{array}$ & $\begin{array}{l}14(4 \cdot 7) \\
34(11 \cdot 5) \\
80(27 \cdot 1)\end{array}$ \\
\hline
\end{tabular}

^Includes Parkinson's disease (ICD 332).

\section{Results}

Four hundred and sixty parkinsonian patients in 64 practices were initially identified through the computerised records. To enable flagging, it was necessary for us to obtain personal details on the subjects from their general practitioner. Two hundred and forty patients were not entered because (a) the general practitioner had either died or moved (65 cases); (b) the general practitioner refused or failed to respond (76 cases); (c) insufficient information was provided on the patient to enable flagging (99 cases). We were therefore left with 220 cases from 40 practices and 421 matched controls. It was not always possible to generate two controls for every case, because of difficulties with flagging. There was no difference in age and sex between subjects that did and did not enter the study.

The median age at entry of the 220 patients was 69.3 (range 32.9-90.7) and of the 421 matched controls $69 \cdot 5$ (range $31 \cdot 5-89 \cdot 7$ ) and there was no difference in the age distribution. There were more women than men: $57 \cdot 7 \%$ for cases and $59 \cdot 4 \%$ for controls. The regional distribution of subjects was as follows: southern England (42.3\% cases, $41.9 \%$ controls), midlands ( $10.0 \%$ cases, $12.3 \%$ controls), northern England (41.9\% cases, $39 \cdot 2 \%$ controls), and Wales (5.9\% cases, $6 \cdot 7 \%$ controls). At 20 years of follow up, 195 cases $(88.6 \%)$ and 295 controls $(70 \cdot 1 \%)$ were no longer alive $\left(\chi^{2}=26.2\right.$ on 1 df $\left.P<0.001\right)$. The median age at death for cases was $77 \cdot 6$ (range 53.8-97.3) years and 83.5 years (range $55 \cdot 0-100 \cdot 1$ ) for controls (Wilcoxon $Z=-6 \cdot 7$ $\mathrm{P}<0.001$ ).

Table 2 presents the causes of death for cases and controls with men and women shown separately. The single largest category of deaths was due to IHD for both cases and controls. Cases were more likely to have a death in the "other" diseases category as this
Figure 1 Kaplan-Meier plot for survival of patients with parkinsonism and controls stratified by sex for 17.5 years of follow up. $P D=$ Parkinson's disease .

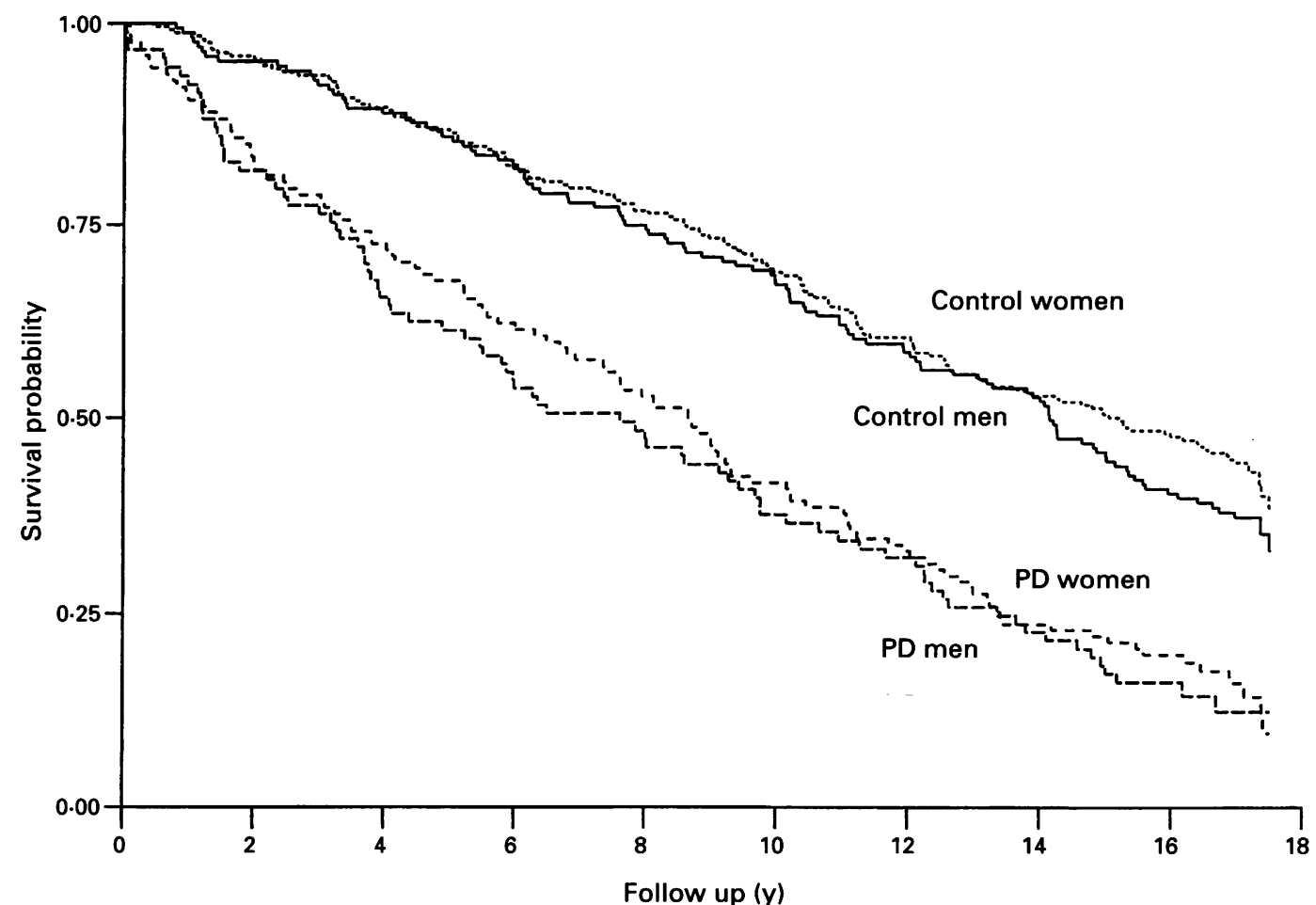


Table 3 Hazard ratios * and 95\% CIs for patients with parkinsonism compared with controls for various causes of death

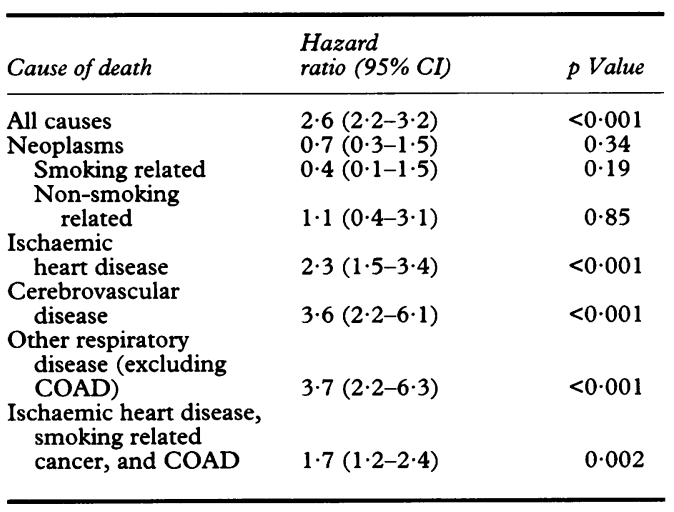

*A value greater than one indicates that patients with parkinsonism have a greater risk of dying. All models have peen adjusted for age, sex, and region. For cerebrovascular been adjusted for age, sex, and region.
disease, age was used as a quadratic term. disease, age was used as a quadratic term.
$\mathrm{COAD}=$ chronic obstructive airways disease.

includes Parkinson's disease (ICD 332) as a cause of death.

Inspection of the Kaplan-Meier survival curve for 20 years of follow up suggested that after around 17.5 years the survival curves seemed no longer proportional (interaction term $\chi^{2}=6.5$ on $1 \mathrm{df} P=0.01$ ). We therefore limited all the survival analyses to a maximum $17 \cdot 5$ years of follow up. The median follow up period was $17 \cdot 2$ (range $15 \cdot 5-17 \cdot 5$ ) years. Figure 1 shows the survival function for cases and controls stratified by sex. The median survival from entry into the study was $7 \cdot 6(95 \%$ CI 5.5-9.7) years for male cases compared with $14 \cdot 1$ years $(95 \%$ CI 12.7-17.2) for male controls. For female cases this was $8.6(95 \%$ CI $6.9-10 \cdot 2)$ years compared with $15 \cdot 2$ (95\% CI $12 \cdot 7-17 \cdot 2)$ years for female controls. Cases had more than a twofold increased risk of dying from

Better mortality Worse mortality

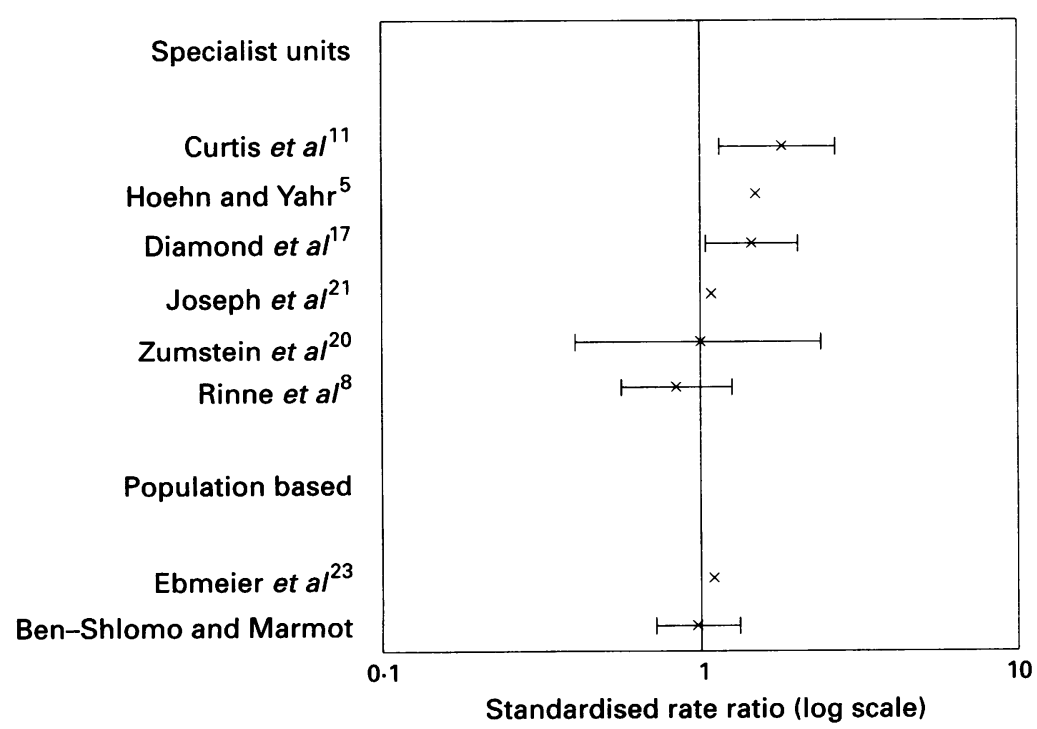

Fig 2 Relative mortality ratios for women compared with men grouped by specialist or population based studies. Bars are confidence intervals. Information was not always available to calculate these. any cause after adjustment for age, sex, and region (table 3 ). There was little difference between men $(2 \cdot 70,95 \%$ CI $2 \cdot 01-3 \cdot 64)$ and women $(2 \cdot 61,95 \%$ CI $1 \cdot 61-3 \cdot 75)$. The hazard ratio varied depending on the cause of death. Parkinsonian cases were more likely to die of IHD, cerebrovascular disease, and other respiratory disease, predominantly bronchopneumonia. There was no significant difference for mortality from neoplasms. This finding was true for both smoking related or non-smoking related neoplasms. Parkinsonian cases were less likely, however, to die from smoking related neoplasms. There were no significant interactions for either sex, region, or age group. There was a general trend that the hazard ratios were greatest for the youngest age group (25-54 years: $3 \cdot 9,55-64$ years: $2 \cdot 8,75-84$ years: $2 \cdot 0,85-94$ years: $2 \cdot 4)$. This shows that life expectancy is reduced relatively more for younger than older cases.

Cases with Parkinson's disease are less likely to smoke $^{22}$ and hence would be expected to have lower mortality from smoking related neoplasms or chronic respiratory disease. As IHD is the most common cause of death, even in non-smokers, ${ }^{23}$ we wondered whether the excess cardiovascular mortality seen for the parkinsonian cases might reflect this lower risk of death from other smoking related diseases (competing cause of death hypothesis). We therefore repeated the analysis using a composite outcome measure of death from ischaemic heart disease, smoking related neoplasms, and chronic obstructive airways disease. This assumes that if subjects had not died from the last two categories, they would have died of IHD instead after exactly the same follow up period. This is the most extreme scenario and is biased in favour of the "competing cause of death" hypothesis. The hazard ratio for this outcome was reduced compared with IHD but still showed that cases had significant excess mortality $(70 \%)$.

\section{Discussion}

Our results are important for two reasons. This cohort of cases was ascertained from primary health care facilities rather than specialised tertiary units. The long follow up period and data on healthy controls enables one to examine the comparative mortality from several causes of death. To the best of our knowledge, this is the first study to report cause specific mortality for parkinsonian cases compared with population based controls. Although only half of all the available cases were recruited into this study, it is unlikely that this introduced any serious bias as failure to enter the study was mainly due to the nonavailability or refusal of the general practitioner and not individual parkinsonian cases, which might have resulted in recruitment bias.

\section{RELATIVE MORTALITY}

We find a greater than twofold increased risk of mortality for parkinsonian cases compared 
with general population controls. Like any cohort study with a long follow up period, however, our results may be "out of date" as they reflect the experience of cases recruited in the early 1970s. As levodopa treatment was generally introduced in the early 1970 s, it is likely that most of these cases would have received levodopa medication, but this may have been at an advanced stage in the natural history of their disease. It is also important to consider possible errors in diagnosis and how they might have affected our results. Two prevalence studies from the United Kingdom provide estimates as to the possible proportion of ascertained cases that were either drug induced $(3.9 \%, 18 \cdot 1 \%)$ or had another condition-for example, benign essential tremor $(8.5 \%, 14.5 \%) .{ }^{24} 25$ Assuming that subjects with benign essential tremor have no increased mortality, the inclusion of some subjects with drug induced Parkinson's disease would bias our results towards increased mortality. Most studies indicate that those with schizophrenia have around twice the mortality risk compared with the general population. ${ }^{2627}$ This is more pronounced in young schizophrenic patients, ${ }^{27}$ and should introduce less bias in this sample. Clinicopathological studies also highlight the difficulties of making an accurate diagnosis of idiopathic Parkinson's disease ${ }^{28}$ and it is likely that some cases of atypical parkinsonism with a worse prognosis were included. Mild parkinsonian cases may also have been underascertained as they could have been less likely to have seen their general practitioner in the study year. For all of these reasons, our estimate of relative mortality may be overly pessimistic.

Doubt still remains over whether the introduction of levodopa has reduced mortality. Some studies have shown little difference in mortality for parkinsonian cases, since drug treatment (see table 1). ${ }^{578}$ Two of these studies were limited to only three years of follow up. With further follow up, the difference in relative mortality has been seen to increase. ${ }^{13}$ A recent analysis from the Olmsted County Project does suggest that patients treated with levodopa have improved survival, especially in the first five years. ${ }^{14}$ Their multivariate analysis attempted to control for selection bias, which is an inherent problem with retrospective observational studies. Their results, however, may still reflect the effects of residual confounding due to measurement error in the confounding variables. ${ }^{29}$ Two other studies have also noted, like ours, a greater than twofold increase in mortality. ${ }^{1316}$ This includes a recent cohort (1984) of cases of Parkinson's disease recruited from a prevalence study in Aberdeen. ${ }^{24}$ Only $8 \%$ of these cases had not received levodopa medication. ${ }^{16}$ Despite more than 10 years between this and our study, the estimates of relative mortality are remarkably similar $(2.6 v 2.4) .^{16}$

DO WOMEN HAVE A WORSE PROGNOSIS?

Another issue of debate is the finding that women have a greater relative mortality than men. This was first noted in the large prelevodopa series of Hoehn and Yahr. ${ }^{4}$ Seven studies have reported sex specific mortality ratios. ${ }^{4510131630}$ Three of these studies have shown worse mortality for women. One possible explanation for these contradictory results is that specialist units enlist relatively more disabled women than men. Indirect support for this idea comes from a study comparing cases of multiple sclerosis ascertained from a neurology unit with a population based survey. Women ascertained from the specialist unit were likely to be more severely disabled than men. ${ }^{17}$ To examine this explanation we have plotted the ratio of female to male standardised mortality ratios and distinguished between specialist unit cohorts and more representative population based cohorts (fig 2). Neither of the two population based cohorts find any sex difference, supporting the idea that the worse survival seen in some studies may be due to the recruitment of more severely disabled women. Similarly the Olmsted County Project found no sex difference in mortality relative to the normal population $^{14}$ (not shown as the data are not given).

\section{CAUSE OF DEATH}

Previous research has only compared total mortality for parkinsonian cases with the general population. Data on the proportion of deaths from specific causes are available, ${ }^{4731}$ but not as cause specific mortality. This is potentially misleading as it is dependent on the relative number of deaths from a specific cause compared with other causes. For example, if the risk of dying from IHD was identical for patients with Parkinson's disease and the general population, mortality from IHD would be identical but the proportion of deaths from IHD to total deaths would seem less as patients with Parkinson's disease are more likely to die of other causes such as bronchopneumonia than controls. This problem is also found when interpreting proportional mortality ratios. Also, because we have follow up data, it is possible to calculate the mortality rate rather than simply the cumulative mortality risk. To illustrate this distinction, imagine that all cases and controls are followed up until death. The proportion of deaths for both groups is identical and the risk ratio is unity. However, if cases are dying at a faster rate than controls, the hazard ratio will be increased.

Studies have suggested that cancer is less common among parkinsonian cases. ${ }^{4132}$ This is not surprising as smoking is less common among patients with Parkinson's disease ${ }^{22} 33$ and therefore the risk of smoking related cancers should be reduced. Our results support this but do not show any difference in the mortality risk for cancers not related to smoking. We believe that lower total cancer mortality is a consequence of smoking behaviour. Respiratory disease, in particular pneumonia but excluding chronic obstructive airways disease, was also more common as a cause of death. This has been noted before ${ }^{34}$ and two possible suggestions for this include central autonomic dysfunction and an effect of med- 
ication on respiratory behaviour. The increase in respiratory deaths is also seen with Alzheimer's disease, ${ }^{35}$ another neurodegenerative disorder, and may reflect a non-specific artifact due to certification behaviour. Only around a third of death certificates that record respiratory disease as the cause of death are validated by necropsy. ${ }^{36}$ This figure is far lower than that for neoplasms (85\%) and ischaemic heart disease $(75 \%) .36$

As IHD is also linked to smoking, ${ }^{19}$ we expected this too to be less common. Surprisingly, the cases had a significantly greater risk of dying from IHD. Previous casecontrol studies have failed to note any increase in cardiovascular disease. ${ }^{37-39}$ These studies simply used self reported histories, however, and not standard methods of ascertaining ischaemic heart disease. One retrospective cohort study noted fewer reports of cardiovascular or cerebrovascular disease for a group of parkinsonian cases than for a hospital group of patients with skin cancer. ${ }^{40}$ Only non-fatal events were recorded, however, by examining the hospital notes of patients attending clinics or seen as inpatients. Furthermore, only the number of events rather than the rate of events was examined.

The increased mortality from IHD is unlikely to be a certification artifact as the IHD false positive rate on death certificates is only $25 \% .^{36}$ We do not believe that this would be systematically biased, so that a case with pre-existing parkinsonism is no more likely to have IHD stated as cause of death than a control. Also, IHD is the most common cause of death, even in non-smokers. ${ }^{23}$ As parkinsonian cases are less likely to die of smoking related diseases because of their smoking behaviour, then they will have to die of another common cause, such as IHD ("competing cause hypothesis"). We do not believe that this explanation is sufficient to explain our findings as even when we compared an extreme scenario by combining death from IHD, smoking related cancers, and chronic obstructive airways disease, the cases still had a greater risk of dying. It has recently been suggested that the inverse association between smoking, Alzheimer's disease, and Parkinson's disease may reflect the differential survival between smokers and non-smokers. ${ }^{41}$ People more susceptible to neurodegeneration and who smoke are less likely to live long enough to develop the disease, whereas those surviving are less susceptible. The inverse association is therefore a sort of "healthy smoker" effect. If our control subjects are less susceptible to IHD, although they have a greater risk of smoking related neoplasms, then this could to some degree explain the apparent increased risk of IHD among cases. The selective mortality hypothesis is inconsistent with other existing evidence, however, from both twin and case-control studies using early onset Parkinsonian cases. ${ }^{42}$ Cerebrovascular mortality was also significantly increased. This is an interesting finding as arteriosclerosis was thought to play a part in the aetiology of Parkinson's disease, ${ }^{43}$ although this is now not generally accepted. ${ }^{37} 39$

CARDIOVASCULAR DISEASE AND PARKINSONISM Several possible explanations for these findings should be considered. (1) They may be simply a chance subgroup finding as no a priori hypothesis existed. Further studies are needed to corroborate these results. (2) An increase in cardiovascular disease may be secondary to the effects of drug treatment. Evidence exists that levodopa lowers blood pressure in hypertensive patients ${ }^{44}$ and of Parkinson's disease cases on long term treatment. ${ }^{45}$ In addition, even parkinsonian cases not on treatment seem to have lower blood pressure than controls. ${ }^{39}$ Several observational and interventional studies have noted an increased risk of cardiovascular deaths with low blood pressure, although this still remains an issue of controversy. ${ }^{46}$ This excess risk is usually small and less than the risk we have found. Levodopa may also induce cardiac arrhythmias via its catecholaminergic actions. The PRADO study randomly allocated cases to levodopa monotherapy or levodopa and bromocriptine. ${ }^{47}$ This study was discontinued after an almost threefold relative risk of death was found in the levodopa monotherapy arm of the trial. The predominant cause of death was cardiovascular disease, including several cases of sudden cardiac death. (3) Both cardiovascular disease and parkinsonism may share common aetiological factors. Recent interest has been focused on the role of oxidative damage in the aetiology of Parkinson's disease through genetic or environmental mechanisms. ${ }^{48}$ Dietary intake of vitamin $\mathrm{E}$, an antioxidant, has been reported to be less in parkinsonian cases, ${ }^{49}$ although no difference has been found in serum concentrations compared with spouse controls. ${ }^{50}$ Indirect evidence exists that antioxidants may have a protective role in preventing IHD. A high intake of vitamin $E$ has also been shown to be associated with a reduced risk of IHD. ${ }^{51}$

Despite the dramatic benefits of levodopa, the relative mortality of parkinsonian cases remains substantial. It is uncertain whether this excess mortality relates to the unaltered natural history of the disease, an adverse effect of treatment, or a common aetiological link between parkinsonism and cardiovascular disease.

$\mathrm{Y}$ B-S is a Wellcome Fellow in Clinical Epidemiology. The UK Parkinson's Disease Association provided financial support for the study.

1 Pollock M, Hornabrook RW. The prevalence, natural history and dementia of Parkinson's disease. Brain 1966;89:429-48.

2 Scigliano G, Musicco M, Soliveri MD, et al. Mortality associated with early and late levodopa therapy initiation in Parkinson's disease. Neurology 1990;40:265-9.

3 Nobrega FT, Glattre E, Kurland LT, Okazaki H Comments on the epidemiology of parkinsonism includComments on the epidemiology of parkinsonism includMinnesota, 1953-1966. In: Barbeau A, Brunette JR, eds. Progress in neurogenetics. Amsterdam: Excerpta

4 Hoehn MM, Yahr MD. Parkinsonism: onset, progression, and mortality. Neurology 1967;17:427-42.

5 Zumstein H, Siegried J. Mortality among parkinson 
patients treated with L-dopa combined with a decarboxylase inhibitor. Eur Neurol 1976;14:321-7.

6 Diamond SG, Markham $\mathrm{CH}$. Present mortality in Parkinson's disease: the ratio of observed to expected deaths with a method to calculate expected deaths. $\mathcal{J}$ Neural Trans 1976;36:259-69.

7 Hoehn MMM. Parkinson's disease: progression and mortality. In: Yahr MD, Bergmann KJ, eds. Advances in neurology. New York: Raven Press, 1986:457-61.

8 Joseph C, Chassan JB, Koch ML. Levodopa in Parkinson's disease: a long term appraisal of mortality. Ann Neurol 1978;3:116-8.

9 Diamond SG, Markham CH. Mortality of Parkinson patients treated with sinemet. Adv Neurol 1979;24: 489-97.

10 Rinne UK, Sonninen V, Siirtola T, Marttila RJ. Long term responses of Parkinson's disease to levodopa therapy. fournal of Neural Transmission 1980;suppl 16:149-56.

11 Cedarbaum JM, McDowell FH. Sixteen-year follow-up of 100 patients begun on Levodopa in 1968: emerging problems. In: Yahr MD, Bergmann KJ, eds. Advances in problems. In: Yahr MD, Bergmann KJ, eds. Advanct

12 Diamond SG, Markham CH, Hoehn MM, McDowel FH, Muenter MD. Effect of age at onset on progression and mortality in Parkinson's disease. Neurology 1989; 39:1187-90.

13 Curtis L, Lees AJ, Stern G, Marmot MG. Effect of L-dopa on course of Parkinson's disease. Lancet 1984;2:211-2.

14 Uitti RJ, Ahlskog JE, Maranganore DM, et al. Levodopa therapy and survival in idiopathic Parkinson's disease: Olmstead County Project. Neurology 1993;43:1918-26.

15 Rajput AH, Offord KP, Beard CM, Kurland LT Epidemiology of Parkinsonism: incidence, classification and mortality. Ann Neurol 1984;16:278-82.

16 Ebmeier KP, Calder SA, Crawford JR, Stewart L, Beeson JAO, Mutch WJ. Parkinson's disease in Aberdeen: survival after 3.5 years. Acta Neurol Scand 1990;81:294-9.

17 Nelson LM, Franklin GM, Hamman RF, Boteler DL, Baum HM, Burks JS. Referral bias in multiple sclerosis research. $\mathcal{f}$ Clin Epidemiol 1988;41:187-92.

18 Morbidity Statistics from General Practice. Second National Morbidity survey 1970-1971. Studies on medical and population subjects No 26. London: HMSO, 1974.

19 Doll R, Peto R. Mortality in relation to smoking: 20 years observations on male doctors. BMF 1976;2:1523-36.

20 Hammond EC. Smoking in relation to the death rates of one million men and women. In: Haenzel W, ed. Epidemiological approaches to the study of cancer and other chronic diseases (National Cancer Institute monograph No 19). Bethesda, MD: National Cancer Institute, 1966:127-204.

21 Morris JA, Gardner MJ. Calculating confidence intervals for relative risks, odds ratios, and standardised ratios and for relative risks, odds ratios, and standardised ratios and
rates. In: Gardner MJ, Altman DG, eds. Statistics with rates. In: Gardner MJ, Altman DG,

22 Marmot MG. Smoking and Parkinson's disease. In: Wald $\mathrm{N}$, Baron J, eds. Smoking and hormone related disorders. New York: Oxford University Press, 1990:135-41.

23 Rose G, Shipley $M$. Effects of coronary risk reduction on the pattern of mortality. Lancet 1990;335:275-7.

24 Mutch WJ, Dingwall-Fordyce I, Downie AW, Paterson JG, Roy SK. Parkinson's disease in a Scottish city. $B M \mathcal{F}$ 1986;292:534-6.

25 Sutcliffe RIG, Prior R, Mawby B, McQuillan WJ Parkinson's disease in the district of the Northampton Health Authority, United Kingdom. A study of prevalence and disability. Acta Neurol Scand 1985;72:363-79.

26 Newman SC, Bland RC. Mortality in a cohort of patients with schizophrenia: a record linkage study. Can $\mathcal{f}$ with schizophrenia: a recor
Psychiatry 1991;36:239-45.

27 Black DW, Fisher R. Mortality in dsm-iiir schizophrenia. Schizophr Res 1992;7:109-16.

28 Hughes AJ, Ben-Shlomo Y, Daniel SE, Lees AJ. What features improve the accuracy of clinical diagnosis in
Parkinson's disease: a clinicopathological study. Neurology 1992;42:1142-6.

29 Phillips AN, Davey Smith G. How independent are "independent" effects? Relative risk estimation when correlated exposures are measured imprecisely. $f$ Clin Epidemiol 1991;44:1223-31.

30 Diamend SG Markam CH, Hoehn MM, McDowell $\mathrm{FH}$, Muenter MD. An examination of male-female $\mathrm{FH}$, Muenter MD. An examination of male-female differences in progression and $m$ ort
disease. Neurology 1990;40:763-6.

31 Marmot MG. Mortality and Parkinson's disease. In: Rose FC, Capildeo R, eds. Research progress in Parkinson's disease. London: Pitman, 1988:9-16.

32 Barbeau A, Joly JG. Parkinson et cancer. Union Med Can 1963;92:169-74.

33 Baron JA. Cigarette smoking and Parkinson's disease. Neurology 1988;36:1490-6.

34 Ebmeier KP, Calder SA, Crawford JR, Stewart L, Besson JAO, Mutch WJ. Mortality and causes of death in idiopathic Parkinson's disease-results from the Aberdeen whole population study. Scott Med f 1990;35:173-5.

35 Newens AJ, Forster DP, Kay DWK. Death certification after a diagnosis of presenile dementia. 7 Epidemiol Community Health 1993;47:293-7.

36 Kircher T, Nelson J, Burdo $H$. The autopsy as a measure of accuracy of the death certificate. $N$ Engl f Med 1985; 313:1263-9.

37 Eadie MJ, Sutherland JM. Arteriosclerosis in Parkinsonism. If Neurol Neurosurg Psychiatry 1964;27: 237-42.

38 Kessler II. Epidemiologic studies of Parkinson's disease. III. A community based survey. $A m \mathcal{f}$ Epidemiol 1972;96:242-54.

39 Martilla RJ, Rinne UK. Arteriosclerosis, hereditary and some previous infections in the aetiology of Parkinson's disease. A case control study. Clin Neurol Neurosurg 1976;79:46-56.

40 Struck LK, Rodnitzky RL, Dobson JK. Stroke and its modification in Parkinson's disease. Stroke 1990;21: 1395-9.

41 Riggs JE. Smoking and Alzheimer's disease: protective effect or differential survival bias? Lancet 1993;342: 793-4.

42 Ben-Shlomo Y. Smoking and neurodegenerative diseases. Lancet 1993;342:1239.

43 Critchley M. Arteriosclerotic parkinsonism. Brain 1929 52:23-33.

44 Saito I, Kawabe H, Hasegawa C, et al. Effect of L-dopa in young patients with hypertension. Angiology 1991;42: $691-5$

45 Iwasaki S, Hamaguchi K, Iwasaki A, Takakusagi $M$ Narabayashi Y. Hypotensive effect of long-term levodopa in patients with Parkinson's disease. Eur Neurol dopa in patien

46 Isles CG, Hole DJ. Is there a J curve distribution for diastolic blood pressure? Clinical and Experimental tolic blood pressure? Clinical

47 Przuntek H, Welzel D, Blumner E, et al. Bromocriptine lessens the incidence of mortality in L-dopa-treated parkinsonian patients: PRADO study discontinued. Eur f Clin Pharmacol 1992;43:357-63.

48 Jenner $\mathrm{P}$, Schapira AHV, Marsden CD. New insights into the cause of Parkinson's disease. Neurology 1992;42. 2241-50.

49 Golbe LI, Farrell TM, Davis PH. Follow-up study of early-life protective and risk factors in Parkinson's disease. Mov Disord 1990;5:66-70.

50 Fernandez-Calle P, Molina JA, Jimenez-Jimenez FJ, et al. Serum levels of alpha-tocopherol (vitamin E) in Parkinson's disease. Neurology 1992;42:1064-6.

51 Rimm EB, Stampfer MJ, Ascherio A, Giovannuci E Colditz GA, Willet WC. Vitamin E consumption and the risk of coronary heart disease in men. $N$ Engl $f$ Med the risk of coronary 